\title{
NOTAS SOBRE UM CASO DE MORTANDADE DE PEIXES, OCORRIDA EM ITANHAEM, SÃO PAULO, BRASIL
}

\author{
LUIS ALBERTO ZAVALA-CAMIN E NAOYO YAMANAKA
}

Divisão de Pesca Marítima, Instituto de Pesca,

São Paulo, SP, Brasil

\section{SYNOPSIS}

A case of fish mortality, the occurrence of 32 species of bony fishes and one species of diatomae, Asterionella japonica at Itanhaem, $S P$, are discussed.

Durante os dias 18 e 19 de abril de 1978, na praia do Município de Itanhaém (São Paulo, Brasil), a partir da cidade do mesmo nome e ao longo de $15 \mathrm{~km}$ de praia em direção à cidade de Peruíbe, grande quantidade de peixes mortos ou moribundos foram jogados pelo mar. A mortandade dos peixes, aparentemente total na área atingida, permitiu um levantamento em que foram identificadas 32 espécies de peixes, apresentadas a seguir em ordem aproximada do habitat, partindo do bentônico ao pelágico: 1) Porichthys porosissimus (mamangá liso), 2) Bascanichthys paulensis, 3) Uma topécie não Identificada da familia Ophichthıdae, 4) Narcine brasiliensis (treme-treme), 5) Trinectes paulistanus (linguado), 6) Epinhephelus guaza (garoupa), 7) Labrisomus nuchipinnis, 8) Bagre marimus. 9) Bagre bagre. 10) Arus spixii. 11) Netuma barba, 12) Sphoeroides greeleyi (baiacu), 13) 1soptstmus parvipinnis (tortinha), 14) 1sopisthus parvi, 15) Larimus breviceps (canguá), 16) Centropomus parallelus (robalo), 17) Cynoscion acoupa (pescada amarela), 18) Cynoscion virescens (pescada branca), 19) Cynoscion striatus (pescada olhuda), 20) Stellifer rastrifer, 21) Stellifer stellifer, 22) Menticirrhus americanus (betara), 23) Macrodon ancylodon (pescada foguete), 24) Genyatremus luteus (canhanha), 25) Ophios. cion punctatissimus, 26) Chaetodiptenus faber (paru), 27) Caranx hippos (xaréu), 28) Mugil curema (parati), 29) Pellona harroweri (sardinha prata), 30) Lycengraulis grossidens (manjuba), 31) An. choa januaria, 32) Anchoa filifera. Os bagres eram as espécies mais abundantes, com aproximadamente $40 \%$ do total e a pescada amarela apresentou os exemplares maiores com até $7 \mathrm{~kg}$ de peso. Também foi encontrado um representante da ordem Equinoida (ouriçodo-mar) e dezenas de exemplares da ordem Clypeasteroida (bolachas-da-praia). Esta diversidade de espécies indica que a causa da morte esteve presente em todas as profundidades e deve ter aparecido de uma torma rápida em toda a área, mpedindo até a fuga dos exemplares de grande porte.

Comparecendo ao local no dia 20 , fomos informados que nos dias 17 e 18 tinham sido observadas manchas marrons no mar, semelhantes às que aparecem após dias chuvosos quando os rios descarregam águas barrentas.

A praia é de areia, com uma extensão total de aproximadamente $20 \mathrm{~km}$, apresentando uma zona de arrebentação de 80 a 100 $\mathrm{m}$ de largura. Foram tomadas quatro amostras de água de 2 litros cada uma; as três primeiras foram realizadas num mesmo local, sendo a primeira (A) coletada na beirada da praia, a segunda (B) na superfície onde tinha $1,20 \mathrm{~m}$ de profundidade e a terceira (C) no fundo, também na profundidade de $1,20 \mathrm{~m}$. A quarta amostra (D) foi coletada em outro local, da mesma forma que a terceira. Essas amostras foram trazidas ao laboratório, e ali fixadas em for$\mathrm{mol}$. Procedeu-se à análise microscópica de subamostras, verificandose que a diatomácea Asterionella japonica foi a dominante em todas as amostras. Os resultados da contagem indicam claramente que houve um "bloom" dessa espécie. Em valores médios foram: A = $111 \mathrm{cels} / \mathrm{ml} ; \mathrm{B}=1507 \mathrm{cels} / \mathrm{ml} ; \mathrm{C}=1849,3 \mathrm{cels} / \mathrm{ml} \mathrm{e} \mathrm{D}=2679$ cels/ml.
O aparecimento de "blooms" em sistema marinho é, geralmente, devido às mudanças na qualidade físico-químico-biótica da água, provocadas por alteraçōes climáticas, Pingree et al (1975) e Fudge (1977). Isto pode ocasionar uma eutroficação do ambiente, a qual favorecerá uma rápida e intensa divisão celular de organismos autotróficos. Em geral, a seqüência é surgir primeiro um "bloom" de diatomáceas, seguindo-se a de dinoflagelados (Tonasi, 1978).

No caso presente, os dinoflagelados foram raros. Contudo, sabe-se que "blooms" destes últimos podem desaparecer completamente em dois dias. Como a amostra da água foi feita dois dias após o acontecimento do fenômeno, é possível que tenham restado apenas as Asterionella.

Segundo Tregouboff \& Rose (1957), Asterionella japonica é uma espécie nerítica, que ocorre predominantemente no período invernal. Um "bloom" desta espécie pode até provocar uma maré vermelha não tóxica, como aconteceu na praia de Hermenegildo (RS), em abril de 1978 (Tommasi, op. cit.). Ainda. sequndo Aubert et al (1966), cit in: Baslow, 1969), A. japonica apresenta substâncias antibióticas que inibem o crescimento de algumas bactérias e de alguns organismos anaeróbicos. Dessa forma, uma alta concentração dessa espécie pode provocar efeitos tóxicos, não só pela liberação dessas substâncias, como também por outras decorrentes da morte e decomposição deste "bloom", que, como no de outras espécies, pode diminuir o teor de oxigênio da água e causar uma intoxicação ou até a morte dos demais organismos.

Em vista de não terem sido realizadas análises químicas da água, não se pode descartar a hipótese de ter havido uma contaminação química. Contudo, os dados sintomáticos registrados em outros locais e neste, e sobretudo, a alta concentração de Aste rionella, levam a acreditar que o "bloom" desta diatomácea tenha sido a mais provável causa da mortandade de peixes ora relatada.

\section{Bibliografia}

BASLOW, M.H. 1969. Marine pharmacology: a study of toxins and other biologically active substances of marine origin. Baltimore, Williams \&Wilkins, xiv $+286 \mathrm{p}$.

FUDGE, H. 1977. The "red tides" of Malta. Mar. Biol., 39(4) 381-386.

PINGREE, R.D.; PUGH, P.R.; HOLLIGAN, P. M. \& FORSTER, G.R. 1975. Summer phytoplankton blooms and red tides along tidal fronts in the approaches to the English Channel. Nature, Lond., 258 (5537) : 672-677.

TOMMASI, L.R. 1978. Maré vermelha. In: Brasil. Ministério da Saúde. Um agravo inusitado à saúde. Brasilia, 279p.

TREGOUBOFF, G. \& ROSE, M. 1957. Manuel de planctonologie méditerranéenne. Paris, C.N.R.S., 2 vol. 